\title{
Ways Selectable to Promote Governmental Purchase of Pension Service
}

\author{
Zhaoxin Wang \\ Southwest University for Nationalities \\ Chengdu, Sichuan, China
}

\begin{abstract}
The governmental purchase of pension service is the output of the transformation of governmental function and the reform of financial systems. In view of the deepening of the aging population across the country and the increased demand for the pension service by the elderly, it has become an urgent problem for the governments to solve on how to innovate approaches and make use of the governmental purchase of services to drive the multiple development of the pension service. Based on the study on the development of governmental purchase of pension service, the paper aims to seek for directions, modes and approaches applicable for the governmental purchase of services in the pension service, and propose corresponding suggestions and measures.
\end{abstract}

Keywords-governmental purchase; pension service; policy applicable; legal construction

\section{INTRODUCTION}

Since the year 2000, with the transformation of governmental functions, the advancement of reform of serviceoriented governments, the governmental purchase of services has been explored and practiced across the country to some degrees. Especially accompanying with the deepening of aging population in the country, it has become much more urgent to introduce the governmental purchase of services into the pension service to the elderly. A typical mode is the governmental purchase of family pension services in Haishu District, Ningbo city, Haishu District People's Government provided financial budget support to the non-profit organization Haishu District Star Nursing Association for purchase of the family pension service of 65 communities, and made overall arrangements to the service-oriented groups, contents and performance evaluation. The governmental purchase of pension services is not only an extension of the governmental function transformation, but also an important way to save financial costs and promote social competition to improve the quality of pension service. The 3rd Plenary Session of the Eighth Central Committee of the Communist Party of China (CPC) clearly pointed out that "To promote the governmental purchase of services, and all the transactional management services should introduce competition mechanism in principle and be purchased from the society through contracting and authorization". In 2014, the Ministry of Finance together with the National Development and Reform Commission et al issued a Notice on Well Doing the Governmental purchase of Pension Service, which formed a

It is a key project innovated by postgraduates of Southwest University for Nationalities. Project No: CX2016SZ004.I frame to regulate the main bodies, objects, contents and methods relating to the service purchase and drove the development of governmental purchase of pension service in the country.

\section{EXPLORING THE GOVERNMENTAL PURCHASE OF PENSION SERVICE AT HOME}

The development of governmental purchase of pension services is based on the extension of governmental purchase of public services. During the exploration of governmental purchase of pension services at home, main problems are the subsidy contents of financial budget and the construction of platforms to undertake the pension services. The explorations in local regions show that the proportion of budget allowances and policies in provinces and cities are relatively uniform but differ in sub-districts governments. Basically the exploration and practice are led by the Ministry of Civil Affairs, after filing at districts, sub-districts and communities, flow report and review, the governments provide subsidies. As for the institutional pension service, generally financial subsidies are provided according to beds and number of the elderly; as for the family pension and retirement communities, financial subsidies and allowances are provided according to the conditions of the elderly and service contents. Some contents of governmental purchase of services are free for the elderly, and some need costs after allowance release. As for the governmental purchase of pension services, the subsidies proportion varies with the budget in different areas.

\section{A. Ji'nan City}

In 2008, Ji'nan Civil Affairs Bureau began to promote the family pension service and provide some of the elderly with services purchased by the government. Ji'nan mainly carried out the governmental purchase of family services. The "Instruction Opinions for Family Pension Service in Ji'nan City" pointed out that the family pension service - orientated objects shall be the elderly who, governed by the sub-districts, own registered household in Ji'nan city, and released six conditions for application. Meanwhile, Ji'nan issued "Family Pension Feedback Card" and "Family Pension Service Card" as basis for financial budget and performance evaluation. As a fallback policy, according to the economic conditions and geographical conditions, the modes and contents of governmental purchase of pension service varied. In 2013, Lixia District Civil Affairs Bureau invested 6 million yuan to 
strengthen the governmental purchase of pension service to provide hour-based family service in four time intervals according to the physical conditions and living conditions of the elderly; yet Changqing District, considering more rural communities existing there, executed the governmental purchase of pension service via product supply and cash coupon. After the year 2013, the purchase budget of Ji'nan city increased the estimated expenditure to the governmental purchase of pension service, and the adjusted Instruction Category to Social Forces for Service Purchase in Ji'nan (Interim) totaled 6 categories, 57 clauses and 321 items, of which, in the category of basic pension service, there are eight items related to the governmental purchase of pension service. As for the institutional pension project, Ji'nan people's government encouraged social forces to establish pension service agencies, and provided subsidies as per beds and conditions of the elderly. Up to the year 2015, more $90 \%$ of apartments for the elderly were invested through private funds. With the aggravation of aging population, Ji'nan had lowered the requirements accessing to the governmental purchase of pension service successively, and innovated the modes and methods such as installation one-key all for family pension service, encouragement of neighboring assistance and construction of daytime care centers in communities, which promoted the upgrade of the family pension service quality in Ji'nan.

\section{B. Wuxi City}

From the year 2007, Wuxi city launched the overall implementation of the governmental purchase of family pension service, and released 360 yuan as family pension service subsidy per month per household to the elderly aged 80 or more in Wuxi city, and family pension service coupons were adopted for the work. As for the financing, Wuxi established a financing mechanism with many channels, including arrangement via the government financial budget, social welfare funds and charitable funds, etc. In 2012, Wuxi Civil Affairs Bureau issued Approaches for Family Pension Service Subsidies in Wuxi City, which clearly defined the subsidy-orientated objects, standards and financing. From the year 2014, Wuxi People's Government started to provide trial family pension support to eight categories of the population, and the service contents mainly include living care, rehabilitation care and spiritual comfort, etc. During the actual operation, Wuxi People's Government continuously promoted the Internet of Things + Family Pension mode and operating system, which benefited the upgrade of the family pension service quality. The Implementation Plan Family Pension Service Support in Wuxi City released by Wuxi People's Government in 2014 (Interim) showed requirements to the service providers, financing channels and operating procedures, and specially indicated contents related to supervision and evaluation. Besides, Wuxi People's Governmental purchased accident insurance for the elderly qualified, which in a large degree, reduced the economic pressure of individuals and families cased by accidental injuries of the elderly. Recently Wuxi People's Government issued the first service standard for family pension at home, namely Code for Family Pension Service Support, which stated normative evaluation criteria to the service contents, flow, standard and quality of service staffs.

\section{Beijing City}

Beijing explored the construction of the pension service system in the year of 2009 earlier, and proposed the "9064" pension service mode, but it started late in the governmental purchase of pension service. The exploration of Beijing on the governmental purchase of pension service focused on the governmental purchase of family pension service, and regarded the purchase service to the disadvantaged groups and the elderly disabled. In 2013, Beijing Haidian District and Beijing Senior Care Service Pension Service Co., Ltd launched the cooperative project "Retirement Communities and Helping the Disabled System Innovation Trial", where the district people's government invested to build a pension and the disabled management service center. In the mode of "public construction for private operation", the district government selected professional pension service agency through bidding to reduce the house rent of institutions. As for the government subsidy, the former increase of number of people was changed to increased of institutions, the government would define conditions and standards for the elders to enjoy subsidies, and professional agencies would provide services. The government mainly played the role of policy making, housing land supply, construction of information platforms and supervision of service course. As for the social pension agencies, according to the nature of profits and non-profits, Beijing's governments would transfer lands and increase subsidies to attract social funds to the market, and further purchase "comprehensive liability insurance for pension service agencies". As for the retirement communities, up to the year 2014, Beijing had introduced 11000 retirement communities and family pension service agencies, which provided the elderly with living care and spiritual comfort totaling 110 services of 6 categories. As for the features, Beijing's governments provided higher financial subsidies, and created a "Fence-free nursing home" family pension mode, and purchased accident insurance for the elderly who were of "Three-loss", "Minimum Living Security" and "Five Guarantees" and so on.

\section{STATUS QUO OF GOVERNMENTAL PURCHASE OF PENSION SERVICE}

\section{A. Lack of Connection between Micro-Level Research and Policy}

There are many studies on the governmental purchase of public services, but few related to the purchase contents and lack in detailed treatment. The study on the governmental purchase of pension service is an important part of the governmental purchase of public service. During the study on the purchase of pension service, it is required to find multiple relations to the society according to the special mode, especially a breakthrough point should be found in the construction of the service undertaking and the combination of supporting policies. Recently though a "Notice on Well Doing the Governmental purchase of Pension Service" was released in the country, which, however, gives no clear instruction to the micro-details and the coordination of various interest 
groups, and the policy floating space is larger, and higher risks exist in the implementation. Due to the special nature of governmental purchase of pension service, the construction of qualification of social organizations, training standards of professional staff service ways and contents as well as performance evaluation and feedback all shall be detailed as branches of governmental purchase of pension service. The governmental purchase of pension service is a systematic project, so relevant supporting policies shall be formulated for regulation. However, the poor combination of policies caused different measures in the implementation, vague interest groups, failure in service performance evaluation and supervision, and further resulted in disqualified service and difficulties to control risks of pension service.

\section{B. Major Problems of Undertakers for the Governmental Purchase of Pension Service}

Undertakers for the governmental purchase of pension service refer to social organizations and institutions which are capable of providing specialized pension service. In China, social organizations generally include various organizations such as non-governmental organizations, non-profit organizations, the third sectors and private organizations. ${ }^{1}$ Currently the undertakers for the governmental purchase of pension service in the country mainly have three problems. First, Non synchronous development exists between social organization and policy promotion. Acting as the significant undertakers for the governmental purchase of pension service, social organizations are a key part to push the governmental purchase of pension service. But, during the actual promotion, the governmental purchase of pension service took on "Internal Treatment" and "Formalistic Operation". 2 On the one hand, the poor construction of social organizations caused high dependence to the government; on the other hand, social organizations face higher barriers against fair competition in markets. Second, the reform in government departments and public institutions goes slowly, which prevent the undertakers from participating in the fair market competition. In 2011, the CPC Central Committee and the State Council issued the Instructions on Pushing the Reforms by Classification in Governmental Departments of Institutions, which clearly pointed out that, after public institutions engaging in the production and operation are chanted to enterprises, those which are engaged in the public service shall be intensified in the nature of public service, both of which are important strength to undertake the governmental purchase of pension service. Yet, it caused mixed functions of the government and enterprises and vague in nature in the actual operation, which was also a key factor causing the "Internal Treatment" of the governmental purchase of pension service. Third, the mode of developing institutional pension service is immature. During the development of governmental purchase of pension service in the country, the family pension and retirement communities are well developed, and little attentions are paid to the

\footnotetext{
${ }^{1}$ Cui Zheng, Wang Yong, Wei Zhonglong, Interaction between Government Purchase of Services and Development of Social Organizations [J]. Chinese Public Administration, Social Management,2012 (8)

${ }^{2}$ Xu Xiaoling, Government Purchase of Services: Status Quo, Problems and Prospect, Empirical Study based on Social Organization in Chinese Mainland [J]. Thinking, 2012 (2).
}

institutional pension service. Up to the year 2015, on the one hand, the elderly fully or partially losing labor abilities in urban and rural areas accounted for $18.3 \%$ of the elderly, totaling about 40.63 million persons; on the other hand, there are 40,000 pension agencies in the country, the bed empty rate in private agencies reached $48 \%$. As for the institutional pension service, on the one hand, there are higher demands from the elderly, on the other hand, the bed empty rate is higher too. Main causes for the problems include four points : first, those who select institutional pension service are most the elderly fully or partially losing labor abilities, and the demand is higher; second, most pension service agencies are built by private organization with high costs and high requirements for financial subsidies, and the elderly have to make high payment; third, the development of social pension service agencies is very slow and in the lake of management experience, and the risk is higher; fourth, the institutional pension service is immature in the country, the entry and exit mechanism is imperfect, disagreeing with the pension thought and concept of the elderly. In a word, there are many problems in the contraction of undertakers, such as judgment standard for service skills of professionals, service training, arrangement of professional service talents and so on, all are urgent to define and solve.

\section{Problems Existing in the Governmental Purchase of Pension Service}

In order to assure the governmental purchase of pension service, except the powerful undertakers, the purchase process shall be defined.

1) Channels blocked for information disclosure: The information disclosure and transparency and unblocked channels are important points to safeguard market players for fair market competition and undertake the governmental purchase of pension service. The on-the-spot survey and investigation show, on the one hand, the governmental purchase of pension service in some areas are not fully disclosed, the market players are inactive to participate in, and policy discrimination is found on selecting the undertakers. Scholars find that due to the public welfare of public service and the needs to develop social organizations, social organizations are generally selected as the undertakers for the purchase of public service. ${ }^{3}$ On the other hand, it is the lack of information between institutions, institutions and service receivers. During the governmental purchase of pension service, the elderly shall have the rights to select the service providers, and resources shall be shared between institutions. The enforcement of rights shall make the elderly know about the institutions, and the fulfillment of obligations shall have information platforms of the elderly created.

2) Lack of service supervision: Service supervision is the responsibilities of the government and also that of the society. In many places, during the purchase of pension services, attentions are only paid to the information collection and performance evaluation on the service result, and little to the

\footnotetext{
${ }^{3}$ Xu Jialiang, Wu Jing, Textual Analysis on Policies of Government Purchase of Public Services [C]. Academic Seminar on Government Purchase of Services (Fudan University), Nov 14, 2015.
} 
supervision of the service course. Especially in the pension service agencies, the pension service staffs flow frequently, and there are few professional nursing staffs in pension service. According to the calculation of relevant departments, currently the number of nursing staffs for the elderly needed will be about 10 million in the country, yet the actual professional nursing staff totals about 20,000 persons in the country, of whom, about 10,000 or less have professional qualification. Therefore, it is urgent to strengthen supervision on the service process, especially on the service staffs.

\section{ACCelerating The Strategy And Method OF The GOVERNMENTAL PURCHASE OF PENSION SER VICE IN THE COUNTRY}

\section{A. Construction in Legal System}

The legal construction is basic measure to safeguard the governmental purchase of pension service and promote the construction and improvement of social pension service system. Attentions shall be paid to the following 9 points. First, detailing and extension of supporting policies for the governmental purchase of pension service; second, construction of performance evaluation systems applicable for the pension services and clarification of centralized budget; third, construction of entry and exit mechanism for social organizations and institutions; fourth, funding sources for the purchase of pension services and subsidies method; fifth, introduction of performance budget mechanism to ensure the rational use of financial fund; fifth, define the role of government: the government shall be the supervisor and policy maker, and the more or less market intervention both fail to achieve the effect as expected; sixth, clearly define relations of factors in the governmental purchase of pension service; eighth, accelerate the release of qualification standard and opinions of pension service staffs; ninth, detailing of items and contents of purchase of pension service to make it easy for performance check and financial budget.

\section{B. Promoting the "Internet+" Application in the Governmental Purchase of Pension Service}

The long-term development of governmental purchase of pension service can not be separated from the application of Internet technologies, which play an irreplaceable role in the construction of network information and protecting the information disclosure. The "Internet + pension service" will not only promote the innovative development of the pension industry, but also safeguard the interest groups to share information in the course of governmental purchase of pension service. The information sharing mainly includes four points: First, performance feedback and check: the final service result shall be reflected through the check result. The performance check needs the satisfaction questionnaire of the service receivers and the complex check of a third party, and the disclosure of the information integration and check result will promote the undertakers in supply capability and quality improvement, which will objectively improve the overall quality of the governmental purchase of pension service. Second, acting as undertakers, the interest groups own opportunities for fair competition. When releasing biding information, the main body of the governmental purchase of pension service shall make information be disclosed and transparent, and guarantee the qualified social organizations or institutions to master information via relevant channels unblocked. Third, keep the information transparent in the competitive bidding. The course of competitive biding and contract establishment shall be disclosed to enable other social organizations or institutions to master basic experience. Fourth, keep the undertakers' qualification and performance capabilities open to the elderly. The undertakers are basic units for the service supply, and their service quality will directly decide the policy achievement of the governmental purchase of pension service, therefore, the elderly shall have the right to make choices as per the qualification of the undertakers, which can be called an extension of the market competition.

\section{Solve the Points on What to Purchase and How to Purchase}

The governmental purchase of pension service mainly consists of three parts: purchase of family pension service, purchase of retirement community service and purchase of institutional pension service "Fig. 1". Due the different contents of pension service purchased, during the bidding, it shall be distinguished as per the characteristics of organizations and institutions. Similarly, in view of the different service contents, the contract establishment and check standards shall vary as well. Therefore, when establishing contracts, it will do badly if the service contents are not kept distinguished only because all belong to the service purchase. Besides, there are some "soft service" existing, for example, the service in psychological comfort shall be distinguished for treatment according to the task, after all, such service is still in the lack of quantifiable standard. Except these points, pertinency shall be kept toward the subsidy standard and support strength. The institutional pension service has higher costs, so the support to relevant organizations and institutions shall be distinguished so as to embody the policy instruction. On the how to purchase, the government shall draft detailed purchase flow and all points including service confirmation, selection tenderees, contract establishment, later service related performance check and so on shall be taken into consideration. On the how to purchase, an outsourcing shall be adopted, directional commission or cooperation shall be specified as per actual conditions. The government shall be a good supervisor, and execute fund prepayment mechanism, and the amount of prepayment shall enable the organization or institutions as newcomers to the market to develop the pension service in a short time as possible as it can, and then make regular payment as per the service performance. Finally at the beginning of the purchase of pension service, the government shall provide efficient to the social organizations or institutions. 


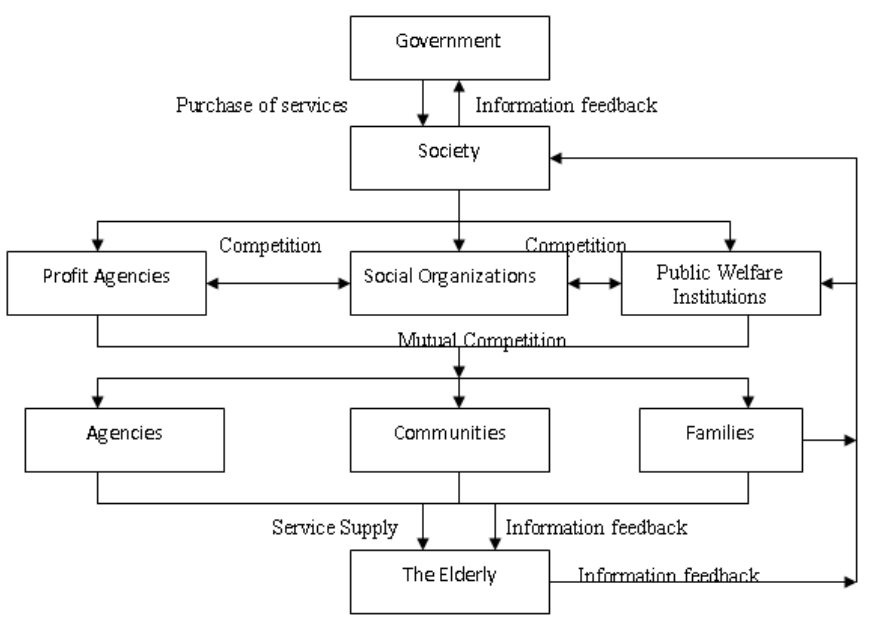

Fig. 1. Flow Chart of Governmental purchase of Pension Service

\section{CONCLUSION}

The governmental purchase of pension service means that relying on the market mechanism, the pension service to be provide by the government and the pension service needed for the government to perform are delivered to qualified social forces via certain methods and procedures, and the government, according to the quantity and quality of the pension service, will make relevant payment. The governmental purchase of pension service in the country consists of governmental purchase of family pension service, governmental purchase of retirement community service and governmental purchase of institutional pension service. Yet the governmental purchase of pension service in the country is still in the initial stage, and the policies in different regions vary, the relations of interest groups are vague, and supporting policies are inadequate, all of which more or less have caused problems in some degree. Therefore, it needs to take the governmental purchase of pension service as a systematic engineering for push carefully, find problems and barriers in the development, improve the system and innovate the modes to solve the problems and promote the development of the governmental purchase of pension service consistent with the national circumstances in the country.

\section{REFERENCES}

[1] Cui Zheng, Wang Yong, Wei Zhonglong, Interaction between Governmental purchase of Services and Development of Social Organizations [J]. Chinese Public Administration, Social Management,2012 (8)

[2] Xu Xiaoling, Governmental purchase of Services: Status Quo, Problems and Prospect, Empirical Study based on Social Organization in Chinese Mainland [J]. Thinking, 2012

[3] Xu Jialiang, Wu Jing, Textual Analysis on Policies of Governmental purchase of Public Services [C]. Academic Seminar on Governmental purchase of Services (Fudan University), Nov 14, 2015. 